\title{
Effect of Alkaline Concentration and Solid Liquid Ratio on the Acid Resistance of Fly Ash Based Geopolymer Mortar
}

\author{
Abel W. Ourgessa ${ }^{1, ~}{ }^{\text {, }}$ Amen Aniley ${ }^{1}$, Ababo G. Gudisa ${ }^{1}$, Ibsa Neme ${ }^{1}$, Alemshet Bekele ${ }^{2}$ \\ ${ }^{1}$ Chemical Engineering Department, Addis Ababa Science and Technology University, Addis Ababa, Ethiopia \\ ${ }^{2}$ Civil Engineering Department, Addis Ababa Science and Technology University, Addis Ababa, Ethiopia

\section{Email address:} \\ abel.woldu@aastu.edu.et (A. W. Ourgessa), amen.aniley@gmail.com (A. Aniley), ababo.geleta@aastu.edu.et (A. G. Gudisa), \\ ibsa3233@gmail.com (I. Neme), alemshet.bekele@aastu.edu.et (A. Bekele) \\ ${ }^{*}$ Corresponding author
}

\section{To cite this article:}

Abel W. Ourgessa, Amen Aniley, Ababo G. Gudisa, Ibsa Neme, Alemshet Bekele. Effect of Alkaline Concentration and Solid Liquid Ratio on the Acid Resistance of Fly Ash Based Geopolymer Mortar. American Journal of Science, Engineering and Technology.

Vol. 4, No. 4, 2019, pp. 80-85. doi: 10.11648/j.ajset.20190404.14

Received: September 5, 2019; Accepted: November 6, 2019; Published: December 19, 2019

\begin{abstract}
Ordinary Portland cement (OPC) is one of the most widely used binders in building materials. However, OPC production is related with high $\mathrm{CO}_{2}$ emission and high energy consumption. Currently geopolymer cements are found to be the alternative substitute for OPC. Geopolymers most commonly are covalently bonded alkali-aluminosilicates which are X-ray amorphous at ambient and medium temperatures. The current study focusses on fly ash which is a byproduct of coal combustion process and due to its amorphous nature and chemistry, it is considered an appropriate raw material for geopolymer synthesis. In this study the effect of alkali concentration and solid liquid ratio on the acid resistance of fly ash based geopolymer mortar was studied. The fly ash was obtained from ayka Addis Textile, Addis Ababa, Ethiopia. Samples were prepared with different solid to liquid ratio and $\mathrm{NaOH}$ molarity and were tested for mechanical and durability properties. It was found that as the molarity of $\mathrm{NaOH}$ solution and solid to liquid ratio increase the initial and final setting time become shorter. Compressive and flexural strength show that after 28 days of curing sample with high Liquid to solid ratio and higher molarity show higher strength and smaller water absorption percentage. Sample were immersed in a $2 \% \mathrm{H}_{2} \mathrm{SO}_{4}$ solution for 25 days and the sample with higher strength with smaller water absorption percentage show higher resistance.
\end{abstract}

Keywords: Cement, Durability, Geopolymers, Fly Ash

\section{Introduction}

Ordinary Portland cement (OPC) is the most commonly used binder in construction application. However, several inherent disadvantages of Portland cement are still difficult to overcome. These are mainly the high energy consumption for the manufacturing process, emission of greenhouse gasses, especially $\mathrm{CO}_{2}$, and durability problems especially in severe environments, acid attack and sea water [1]. The cement industry contributes about $5-8 \%$ of the total worldwide $\mathrm{CO}_{2}$ emissions [2]. The annual production of OPC is $3 \mathrm{Gt} / \mathrm{yr}$. [3]. The projections for the global demand of Portland cement show that in the next 40 years it will have a twofold increase reaching $6 \mathrm{Gt} /$ year. Since OPC production results in a large $\mathrm{CO}_{2}$ emission, geopolymer binders have emerged as one of the possible alternatives for OPC. Geopolymerisation or alternatively named inorganic polymerization, relies on the use of natural materials or industrial byproducts that only need minimal processing, resulting in carbon footprint reduction up to 70 or $80 \%$, and energy consumption reduction of 43 to $59 \%$ [4].

Geopolymers are covalently bonded chains or networks, most commonly alkali-alumino-silicates, which are X-ray amorphous at ambient and medium temperatures and X-ray crystalline at temperatures $>500^{\circ} \mathrm{C}$. They can be synthesized from $\mathrm{Si}-\mathrm{Al}$ rich, commonly amorphous precursor materials, such as calcined clays, volcanic glasses and metallurgical slags and ashes, in combination with an alkaline activating solution, which is often a mixture of $(\mathrm{Na}, \mathrm{K})$ hydroxides and soluble silicates $[4,5]$. The dissolution of the aluminosilicate source by alkaline hydrolysis results in complex silicates, aluminates and 
aluminosilicates which create a supersaturated aluminosilicate solution. The oligomers in the solution form a network by condensation and a gel is produced. Further release of water leads to rearrangement and reorganization of the gel system resulting in a three dimensional aluminosilicate network of a geopolymer [6]. Geopolymers have high strength, low thermal conductivity, high volume stability as well as resistance to chemical, fire and harsh environmental effects [7]. Properties of geopolymers mainly depend on the nature and concentration of the activator $(\mathrm{K}$ or $\mathrm{Na})$, the curing temperature and the humidity [8].

A potential raw material for geopolymerisation is fly ash, a residue of coal combustion for electricity and power production. The pozzolanic property of fly ash makes it a resource for making cement and other ash based products. The major constituents of most of the fly ashes are Silica $\left(\mathrm{SiO}_{2}\right)$, alumina $\left(\mathrm{Al}_{2} \mathrm{O}_{3}\right)$, ferric oxide $\left(\mathrm{Fe}_{2} \mathrm{O}_{3}\right)$ and calcium oxide $(\mathrm{CaO})$. The other minor constituent of the fly ash are $\mathrm{MgO}, \mathrm{Na}_{2} \mathrm{O}, \mathrm{K}_{2} \mathrm{O}, \mathrm{SO} 2, \mathrm{MnO}, \mathrm{TiO}_{2}$ and un-burnt carbon. Even though there are no detailed studies on fly ash based geopolymer concretes durability some studies have shown that this concretes show promising performances against severe situations [9]. Fly ash based geopolymer concrete immersed in a sulfate solution shows no change in strength after 150 days of immersion [10]. The materials are also found to be better than OPC concrete in fire resistance [5] and acid resistance [11].

This study mainly focus on the effect of solid to liquid ratio and molarity of alkaline solution on the setting time and acid resistance of fly ash based geopolymer mortar.

\section{Materials and Methods}

\subsection{Materials}

Fly ash was collected from Ayka Addis textile factory power plant and crushed to a size $<63 \mu \mathrm{m}$ using a disc mill. The density of the fly ash powder was $2.3 \mathrm{~g} / \mathrm{cm}^{3}$. The chemical composition of the fly ash is given on table 1 . Analytical grade $\mathrm{NaOH}$ and distilled water were mixed to give $8 \mathrm{M}, 10 \mathrm{M}$ and $12 \mathrm{M} \mathrm{NaOH}$ solution and allowed to cool for $24 \mathrm{hr}$. The activating solution was prepared from sodium silicate $\left(\mathrm{Na}_{2} \mathrm{SiO}_{3}\right)$ mixed with the respective $\mathrm{NaOH}$ solutions in 1:1 ratio. River sand was sieved and cleaned to remove slit and was used as an agregate.

Table 1. Composition of fly ash.

\begin{tabular}{ll}
\hline Content & Composition (wt \%) \\
\hline $\mathrm{SiO}_{2}$ & 60.4 \\
$\mathrm{Al}_{2} \mathrm{O}_{3}$ & 29.31 \\
$\mathrm{Fe}_{2} \mathrm{O}_{3}$ & 5.62 \\
$\mathrm{CaO}$ & 1.18 \\
$\mathrm{MgO}$ & 0.36 \\
$\mathrm{SO}_{3}$ & 0.1 \\
$\mathrm{H}_{2} \mathrm{O}$ & 2.6 \\
\hline
\end{tabular}

\subsection{Sample Preparation}

Nine sets of samples were prepared to study the effect of
$\mathrm{NaOH}$ molarity and activating solution to fly ash ratio (AS/FA) on acid resistance. The mix ratio of the fly ash geopolymer mortar was presented on table 2. The sample preparation for the mortar was as follows. Fly ash powder was mixed with activating solution in a mixer for $2 \mathrm{~min}$ and sand was added 3times the amount of fly ash and mixed again for $4 \mathrm{~min}$. the mix was spoon to a mold of size $4 \times 4 \times 16 \mathrm{~cm}$ and tapped mechanically for a better compaction. The samples are allowed to cure for $24 \mathrm{hr}$ at ambient temperature and demolded. Pastes of the fly ash and activating solutions are made for studying setting time.

\subsection{Sample Characterization}

Vicat apparatus was used to determine initial and final setting time for the geopolymer paste with different Molarity of $\mathrm{NaOH}$ and AS/FA ratio. Vicat apparatus with $1 \mathrm{~mm}$ diameter needle was used to determine initial setting time. Time was measure as soon as fly ash and activating solution were mixed. The penetration height was measured every 10 min till $25 \mathrm{~mm}$ penetration was found. Vicat apparatus with a needle having circular cutting edge of $5 \mathrm{~mm}$ in diameter and set of $0.5 \mathrm{~mm}$ behind the tip of the needle were used to determine final setting time. As soon as the circular edge mark becomes invisible final setting time was registered. Uniaxial compressive strength and uniaxial flexural strength were measured after 2, 7 and 28 days of curing.

Compressive strength teste was measured at maximum load of $100 \mathrm{KN}$ and head displacement of $2 \mathrm{~mm} / \mathrm{min}$. The two halves remaining after the flexural strength test were used for compressive strength test. Water absorption testes were made on samples cured after 28days. The samples were first dried and weighed accurately and placed in a water bath. After $3 \mathrm{hrs}$ they were removed from the water bath, the surface was dried with a soft paper and weighed accurately. The difference in weight was used to calculate the percentage of water absorption. In order to study the resistance on the specimens to an acidic condition accelerated durability test was performed. The mass of the 28 days cured samples were measured and are immersed in a $2 \% \mathrm{H} 2 \mathrm{SO} 4$ solution. After 25 days of immersion samples were removed dried and weighed. Mass loss was used to compare the resistance.

\section{Results and Discussion}

\subsection{Setting Time}

The setting time vs the penetration height was presented in fig 1. Short initial and final setting time was observed on the $12 \mathrm{M}$ solution with AS/FA ratio of 0.9 while longer initial and final setting time was observed on the $8 \mathrm{M}$ and AS/FA ratio 1.2. It can be seen that as the amount of activating solution increases the setting time also increase since as liquid amount increase hardening of the pastes becomes lower. The reason behind is that high amount of soluble silica in the solution so that the reaction takes longer time as reported by Ahmer Ali [15]. The relation between alkalinity and initial setting time was shown in figure 2. It can be seen that as the molarity 
increases setting time decreases. The final setting time also shows the same trend. This can be due to the geopolymerisation reaction. As the amount of $\mathrm{Na}^{+}$increases gel formation fastens and there will be faster hardening.

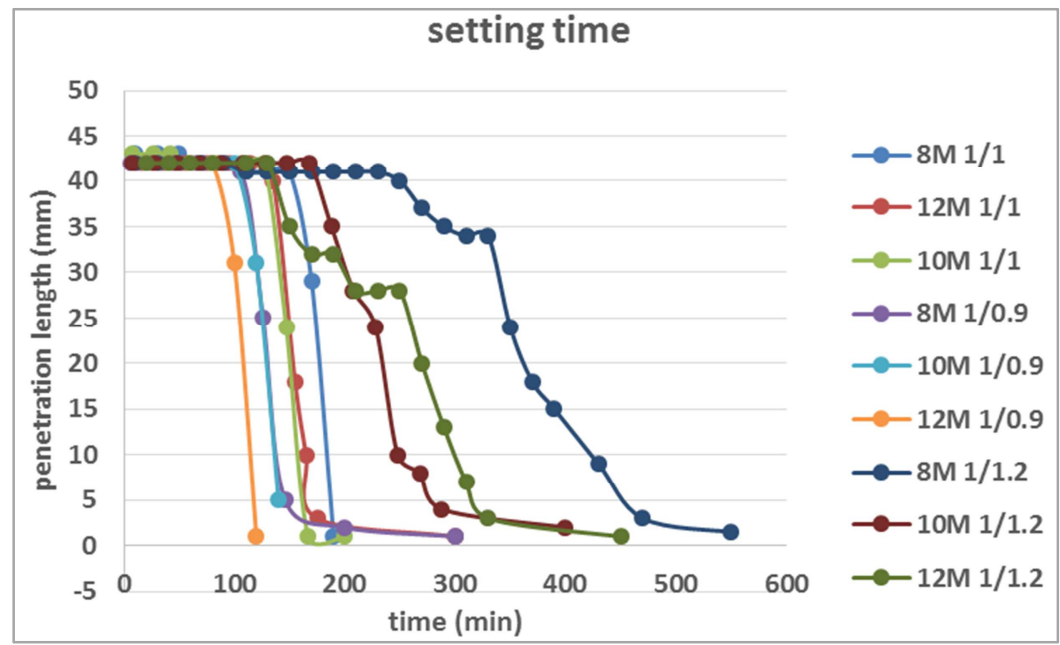

Figure 1. Setting time results.

\subsection{Strength Result}

The 2, 7 and 28 days of flexural and compressive strength results are shown on figures 3 and 4 respectively. After 28days of curing samples with $12 \mathrm{M}$ and AS/FA ratio 1.2 show higher strength in both flexural and compressive strength. It can be seen that samples with higher molarity and higher AS/FA ratio show higher strength. The strength development through the curing days doesn't show much increment for each parameter but there is a 3 to 4.5 time's increment in strength when the AS/FA ratio was increased from 0.9 to 1.2. The result have shown that compressive and flexural strength increase as concertation of alkali increases.

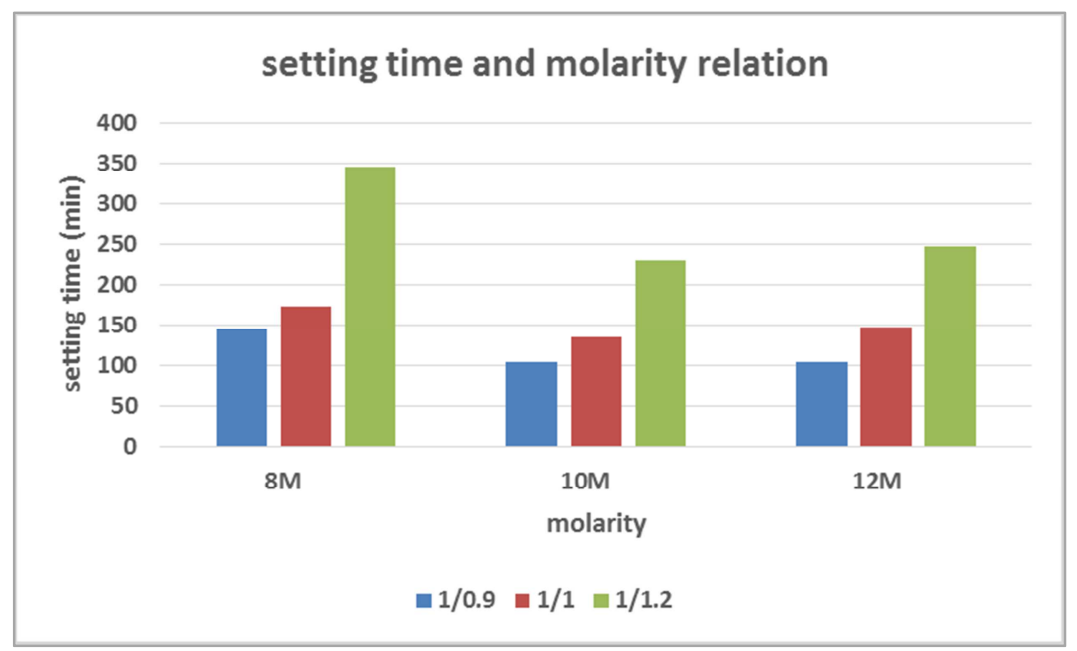

Figure 2. Relation between initial setting time and molarity.

\subsection{Water Absorption}

The water absorption result is presented in figure 5. The result shows that water absorption decreases as the molarity and AS/FA ratio increases. This is due to pore distribution in samples with lower liquid tends to be high and binding ability with sand particles becomes lower as the molarity decreases. And it can be said that lower water absorption means the availability of cracks and voids are smaller. From figure 2 and figure 3 it can be concluded that sample $12 \mathrm{M}$ 91/1.20 has lower water absorption percentage and higher strength. Therefore lower water absorption results in higher strength. It is reported that a higher concentration of $\mathrm{NaOH}$ is the main factor for increased compressive strength [12] and is also related with lower water absorption percentage [13].

Table 2. Mix design ((FA/AS- fly ash to activating solution ratio).

\begin{tabular}{lll}
\hline Sample code & Molarity of NaOH & (AS/FA) \\
\hline $8 \mathrm{M}(1 / 0.9)$ & & 0.9 \\
$8 \mathrm{M}(1 / 1)$ & $8 \mathrm{M}$ & 1 \\
$8 \mathrm{M}(1 / 1.2)$ & & 1.2 \\
$10 \mathrm{M}(1 / 0.9)$ & & 0.9 \\
$10 \mathrm{M}(1 / 1)$ & $10 \mathrm{M}$ & 1 \\
$10 \mathrm{M}(1 / 1.2)$ & & 1.2 \\
$12 \mathrm{M}(1 / 0.9)$ & & 0.9 \\
$12 \mathrm{M}(1 / 1)$ & $12 \mathrm{M}$ & 1 \\
$12 \mathrm{M}(1 / 1.2)$ & & 1.2 \\
\hline
\end{tabular}




\subsection{Acid Resistance}

The weight loss percentage of samples after exposer to $2 \%$ $\mathrm{H}_{2} \mathrm{SO}_{4}$ is presented in figure 5 . I $\mathrm{t}$ can be seen that $12 \mathrm{M}$ and AS/FA $=0.9$ show smaller mass loss than the others. Therefore higher molarity and higher activating solution to fly ash ratio results in better resistance in acidic environment.
The acid resistance is related with strength and water absorption. Sample with $12 \mathrm{M}$ and AS/FA $=0.9$ is found to be higher in strength and less water absorption. It is also reported by Xioa (2016) that acid attack is associated with substitution of $\mathrm{Na}^{+}$by $\mathrm{H}^{+}$or $\mathrm{H}_{3} \mathrm{O}$ resulting in depolymerization of alumino silicate network structure and the liberation of silicic acid [14].

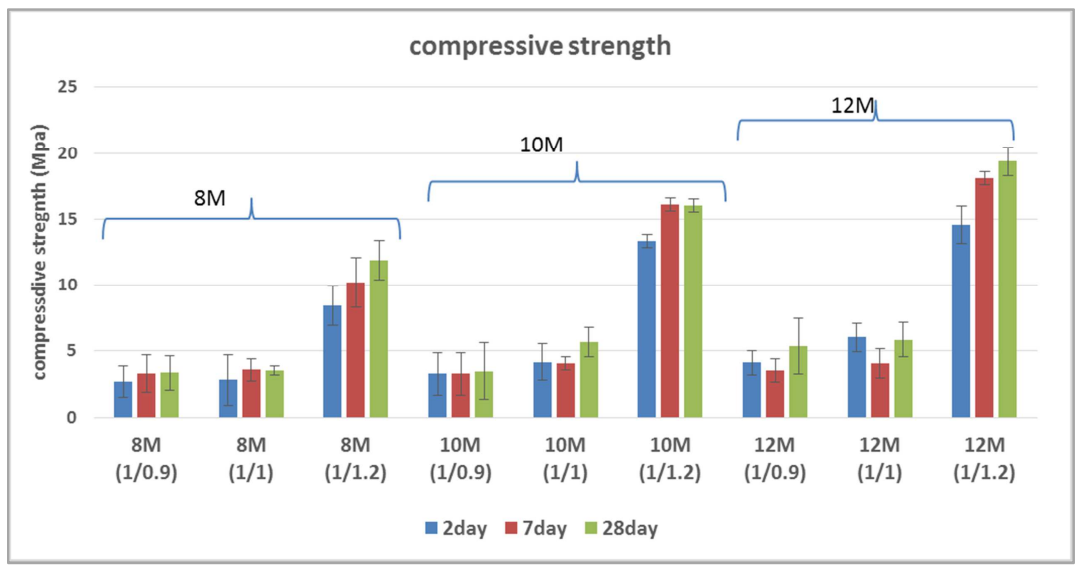

Figure 3. Compressive strength of Fly ash geopolymer mortars.

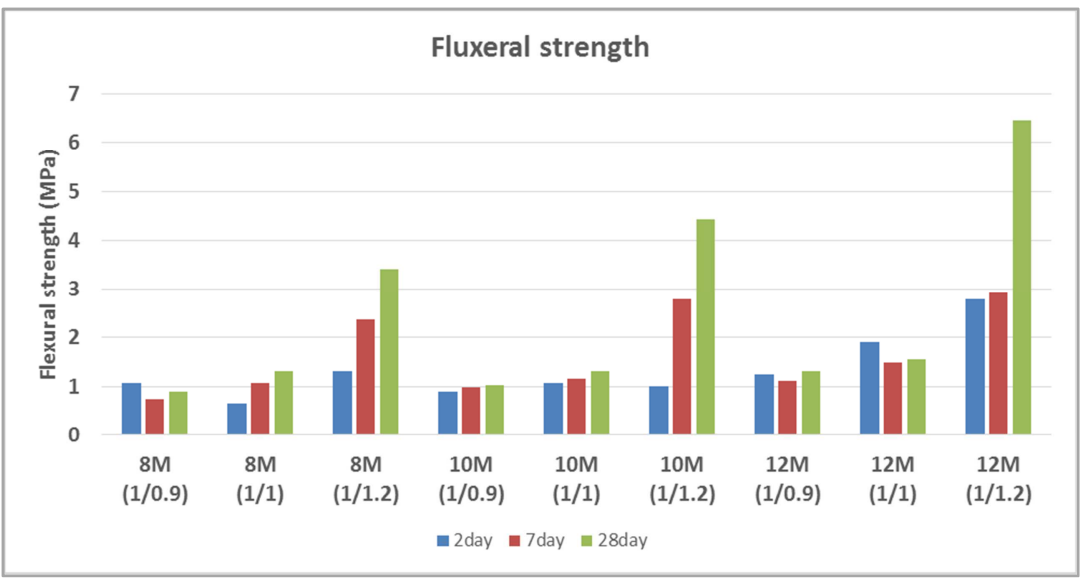

Figure 4. Flexural strength of Fly ash geopolymer mortars.

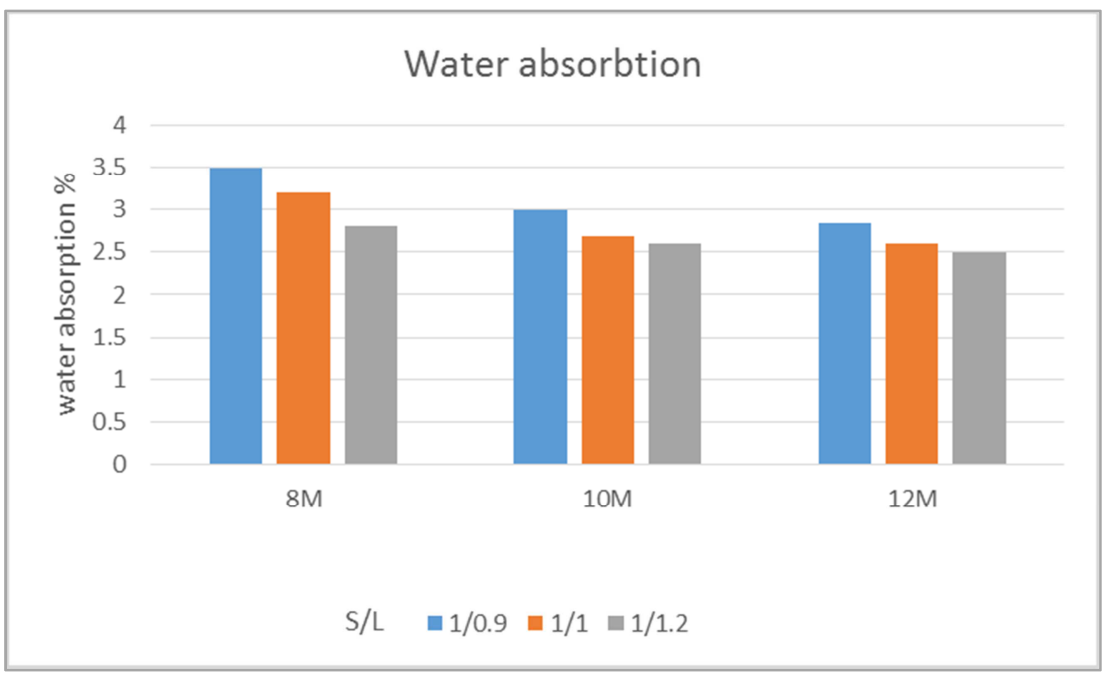

Figure 5. Water absorption result. 


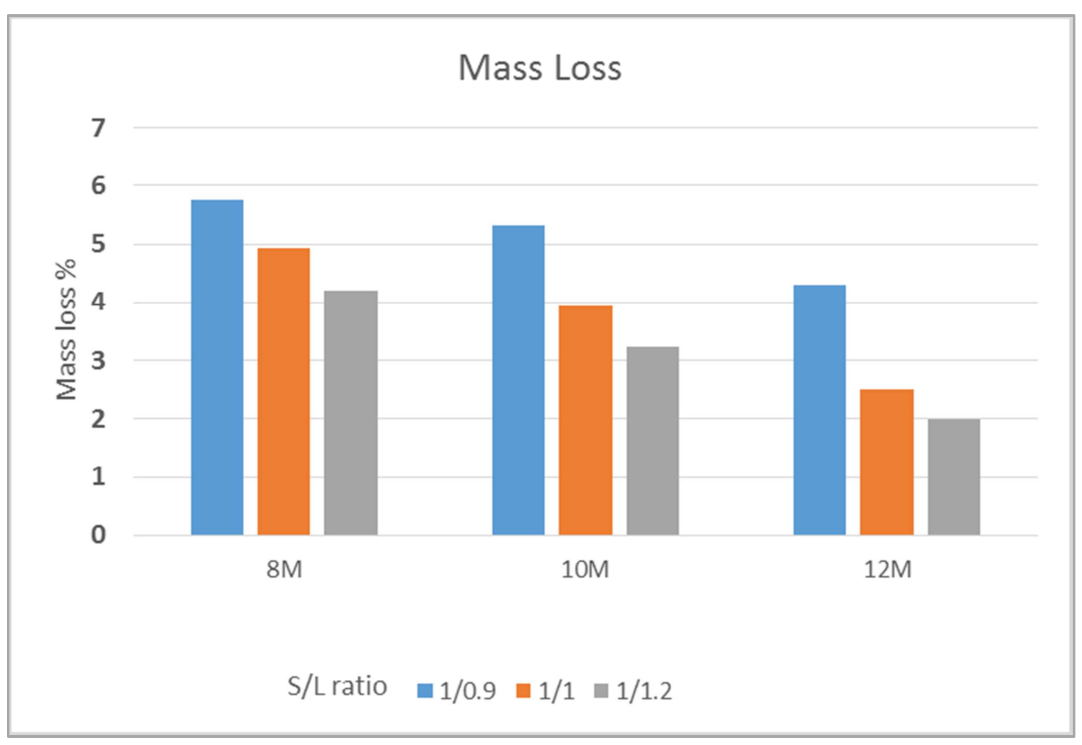

Figure 6. Mass loss of fly ash geopolymer mortars after 25 days of submersion in $2 \% \mathrm{H}_{2} \mathrm{SO}_{4}$.

\section{Conclusion}

In this work the effect of solid liquid ratio and molarity of $\mathrm{NaOH}$ on acid resistance of fly ash based geopolymer mortar was studied. After 28 days of curing it was found that higher strength and better acid resistance can be achieve when the molarity of the $\mathrm{NaOH}$ is higher, higher liquid to solid ratio and lower water absorption capacity. The above result showed that the fly ash produced from the coal power plant of Ayka Addis textile has a potential to be an alternative building material. Further Studying is required on the effect of curing temperature, microstructure and pore size distribution of the geopolymer mortar.

\section{Acknowledgements}

The Authors like to thank Addis Ababa Science and Technology University (AASTU) for providing the fund to execute the first phase of the project. Also thank you for the department of chemical Engineering and department of Civil engineering of AASTU. In Addition the acknowledgment goes to Lina Alayu, Betelhem Tamru and Melat Mengesha.

\section{References}

[1] Sun, P., \& Wu, H. C. (2013). Chemical and freeze-thaw resistance of fly ash-based inorganic mortars. Fuel, 111, 740 745 .

[2] Huntzinger, D. N., \& Eatmon, T. D. (2009). A life-cycle assessment of Portland cement manufacturing: comparing the traditional process with alternative technologies. Journal of $\begin{array}{llll}\text { Cleaner } & \text { Production, } & 17 & \text { (7), 668-675. }\end{array}$ http://doi.org/10.1016/j.jclepro.2008.04.007

[3] Pacheco-Torgal, F., Abdollahnejad, Z., Camões, a. F., Jamshidi, M., \& Ding, Y. (2012). Durability of alkali-activated binders: A clear advantage over Portland cement or an unproven issue? Construction and Building Materials, 30,
400-405. http://doi.org/10.1016/j.conbuildmat.2011.12.017

[4] Xu, H., \& Van Deventer, J. S. J. (2000). The geopolymerisation of alumino-silicate minerals. International Journal of Mineral Processing.

[5] Prof. Dr. Joseph Davidovits. (2002). Environmentally Driven Geopolymer Cement Applications. Geopolymer 2002 Conference, (6), 1-9.

[6] Machiels, L., Arnout, L., Jones, P. T., Blanpain, B., \& Pontikes, Y. (2014). Inorganic polymer cement from fe-silicate glasses: Varying the activating solution to glass ratio. Waste and Biomass Valorization, 5 (3), 411-428. http://doi.org/10.1007/s12649-014-9296-5

[7] Topçu, İ. B., Toprak, M. U., \& Uygunoğlu, T. (2014). Durability and microstructure characteristics of alkali activated coal bottom ash geopolymer cement. Journal of Cleaner Production, 81, 211-217. http://doi.org/10.1016/j.jclepro.2014.06.037

[8] Querol, X., Moreno, N., Umaa, J. C., Alastuey, A., Hernández, E., López-Soler, A., \& Plana, F. (2002). Synthesis of zeolites from coal fly ash: an overview. International Journal of Coal Geology, 50 (1-4), 413-423.

[9] Thokchom, S., Ghosh, P., \& Ghosh, S. (2009). Effect of water absorption, porosity and sorptivity on durability of geopolymer mortars. Journal of Engineering and Applied Sciences, 4 (7), 28-32.

[10] Bakharev, T. (2005). Durability of geopolymer materials in sodium and magnesium sulfate solutions. Cement and Concrete Research, $35 \quad$ (6), 1233-1246. http://doi.org/10.1016/j.cemconres.2004.09.002

[11] Provis, J. L., \& van Deventer, J. S. J. (2009). Geopolymers: structure, processing, properties and industrial applications. Boca raton Boston New York Washington, DC. http://doi.org/10.1533/9781845696382

[12] Pimraksa, K., P. Chindaprasirt, A. Rungchet, K. SagoeCrentsil, and T. Sato, Lightweight geopolymer made of highly porous siliceous materials with various $\mathrm{Na} 2 \mathrm{O} / \mathrm{Al} 2 \mathrm{O} 3$ and $\mathrm{SiO} 2 / \mathrm{Al} 2 \mathrm{O} 3$ ratios. Materials Science and Engineering: A, 2011. 528 (21): p. 6616-6623. 
[13] Bakkali, H., M. Ammari, and I. Frar, NaOH alkali-activated class $\mathrm{F}$ fly ash: $\mathrm{NaOH}$ molarity, Curing conditions and mass ratio effect. Journal Materials Environment Science, 2016. 7: p. $397-401$.

[14] Xiao YuZhuang, Xiao Yu Zhuang, Liang Chen, Sridhar Komarneni d, Chun Hui Zhou, Dong Shen Tong, Hui Min Yang, Wei Hua Yu, Hao Wang, Fly ash-based geopolymer: clean production, properties and applications, journal of cleanrer production 125 (2016) 253-267.

[15] Ahmer Ali Siyal, Khairun Azizi Azizli, Zakaria Man, Hafeez Ullah, Effects of Parameters on the Setting Time of Fly Ash Based Geopolymers Using Taguchi Method, 4th International Conference on Process Engineering and Advanced Materials, Procedia Engineering 148 (2016) 302-307. 